\title{
HUBUNGAN KUALITAS TIDUR DENGAN PENINGKATAN TEKANAN DARAH PADA REMAJA DI SEKOLAH MENEGAH ATAS (SMA) NEGERI 2 LHOKSEUMAWE
}

\author{
Ahmad Sabiq $^{1}$, Julia Fitriany ${ }^{2}$, Mauliza $^{3}$ \\ ${ }^{1}$ Program Studi Kedokteran Fakultas Kedokteran, Universitas Malikussaleh \\ ${ }^{2,3}$ Bagian Ilmu Kesehatan Anak, Fakultas Kedokteran, Universitas Malikussaleh \\ Corresponding Author : ahmadsabiq01@gmail.com
}

\begin{abstract}
Abstrak
Masa remaja merupakan masa transisi dari masa anak ke masa dewasa.Masa ini juga terjadi perubahan dramatis dalam pola tidur-siaga yang mengakibatkan terjadinya perubahan kematangan pada kualitas tidur mereka. Perubahan kualitas tidur pada masa remaja mempengaruhi sistem kardiovaskular dan tekanan darah.Kualitas tidur dapat diukur dengan kuesioner PSQI.Penelitian bertujuan untuk mengetahui hubungan kualitas tidur terhadap peningkatan tekanan darah pada remaja di sekolah menengah atas (SMA) Negeri 2 Lhokseumawe. Jenis penelitian ini adalah observasi analitik dengan pendekatan cross sectional.Penelitian ini dilaksanakan di bulan Agustus 2015 sampai dengan April 2016.Jumlah sampel yang diambil sebanyak 88 siswa yang memenuhi kriteria inklusi dan eksklusi.Analisis univariat digunakan untuk melihat gambaran kualitas tidur dan tekanan darah berdasarkan usia dan jenis kelamin. Analisis bivariat menggunakan pearson chisquare.Hasil penelitian memperlihatkan tidak terdapat hubungan yang signifikan antara kualitas tidur terhadap peningkatan tekanan darah pada remaja di SMA Negeri 2 Lhoksesumawedengan $p$ value sebesar $p=0,231$.
\end{abstract}

Kata Kunci: masa remaja; kualitas tidur; tekanan darah 


\title{
RELATIONSHIP BETWEEN SLEEP QUALITY AND THE INCREASE OF BLOOD PRESSURE ON ADOLESCENCE IN SMA NEGERI 2 LHOKSEUMAWE
}

\begin{abstract}
Adolescence is a transition period from childhood into adulthood. In this period also occurred dramatic change of sleep-wake pattern that can alter the maturation of their sleep quality. The alteration of sleep quality in adolescence is able to give influence to cardiovascular system and also the blood pressure. The sleep quality can be determined by using PSQI questionnaire. This study aimed to discover the relationship between sleep quality with the increase of blood pressure on adolescence in SMA Negeri 2 Lhokseumawe. This was an observational analytic study with cross sectional approach. This study conducted from August 2015 up to April 2016. About 88 samples involved in this study which already fulfilled inclusion and exclusion criteria. The univariate analysis use to describe the sleep quality and blood pressure levels according to the age and sex. Bivariate analysis using pearson chi-square. The result showed that there was no significant relationship between sleep quality and the increase of blood pressure in SMA Negeri 2 Lhokseumawe with $p=0,231$.
\end{abstract}

Key words: adolescence;sleep quality; blood pressure 


\section{PENDAHULUAN}

Masa remaja sering kali dihubungkan dengan mitos dan stereotip mengenai penyimpangan dan ketidakwajaran.Hal tersebut dapat dilihat dari banyaknya teori-teori perkembangan yang membahas ketidaksesuaian, gangguan emosional dan gangguan perilaku sebagai akibat dari tekanan yang dialami remaja karena perubahan-perubahan yang terjadi pada dirinya maupun perubahan lingkungan.Sejalan dengan perubahan yang terjadi dalam diri remaja, mereka juga dihadapkan pada tugas-tugas yang berbeda dari tugas pada masa kanak-kanak ${ }^{1}$.

Masa remaja merupakan masa transisi (peralihan) dari masa anak ke masa dewasa yang berlangsung lama dan berbeda waktu kematangannya antara pria dan wanita. Usia kematangan pada pria terjadi pada umur 20 sampai 22 tahun, sedangkan pada wanita 1 sampai 2 tahun lebih dahulu sehingga menimbulkan masalah dalam hubungan sosial ${ }^{2}$. Remaja sering dianggap sebagai periode yang paling sehat dalam siklus kehidupan, akan tetapi untuk tercapainya tumbuh kembang remaja yang optimal tergantung pada potensial biologinya. Tingkat tercapainya potensi biologi seseorang remaja merupakan hasil interaksi faktor genetik dan lingkungan biopsikososial ${ }^{1}$.Masa ini juga terjadi perubahan dramatis dalam pola tidur-siaga yang mengakibatkan terjadinya perubahan kematangan pada pola tidur mereka. Perubahan kematangan pola tidur pada masa remaja menunjukkan bahwa antara tahap kematangan seks (sex maturation rating system [SMRs]) 3 dan 4 pada remaja pertengahan (usia 14 sampai 16 tahun menurut perkembangan biologis) terdapat peningkatan rasa kantuk pada siang hari dan penurunan latensi atau kebiasaan tidur ${ }^{3,4}$. Waktu tidur yang dibutuhkan bagi remaja usia 11 sampai 18 tahun sekitar delapan sampai sembilan setengah jam pada malam setiap harinya ${ }^{5,4}$.

Penelitian eksperimental yang dilakukan pada tahun 1896 dengan membiarkan subyek penelitian tidak tidur selama 90 jam ditemukan penurunan ketajaman sensoris, reaksi, kecepatan motorik dan memori pada subyek. Saat tidur dibatasi hanya 4 jam dalam 6 malam, terlihat jelas perubahan toleransi karbohidrat, peningkatan tonus simpatis, peningkatan sekresi kortisol, dan penurunan kadar tirotropin. Kurang tidur dapat juga mempengaruhi sistem kardiovaskular dan tekanan darah (TD) ${ }^{6}$. Hasil penelitian cross sectional Asmarita ${ }^{7}$, didapatkan bahwa pada kualitas tidur yang buruk risiko terjadinya hipertensi lebih tinggi dibandingkan dengan yang memiliki kualitas tidur baik pada pasien hipertensi di rumah sakit umum daerah Karanganyar. 
Prevalensi hipertensi remaja di Amerika Serikat meningkat dari 1\% hingga 5\% dari tahun 1989 sampai 2002. Menurut laporan Riset kesehatan dasar tahun 2007, prevalensi hipertensi pada remaja di indonesia sebesar 8,4\% dan $14 \%$ pada remaja di provinsi Riau yang memiliki angka tertinggi dengan prevalensi yang ada di Indonesia ${ }^{8}$.

Data prevalensi mengenai hipertensi esensial secara klinis sangat sedikit didapat pada masa kanak-kanak dan remaja dibanding pada dewasa, namun cukup banyak bukti yang menyatakan bahwa hipertensi esensial pada orang dewasa dapat berawal pada masa kanak-kanak dan remaja.Angka kejadian hipertensi pada anak dan remaja antara 1 sampai 3\%. Sinaiko menjelaskan dalam penelitiannya terhadap 14.686 orang anak berusia 10 sampai 15 tahun menemukan 4,2\% anak mengalami hipertensi. Kurang dari lima persen anak dengan proporsi lebih besar pada remaja, mengalami hipertensi pada satu kali pengukuran tekanan darah. Angka kejadian hipertensi pada anak dan remaja di Indonesia bervariasi dari $3,11 \%$ sampai $4,6 \%{ }^{9}$.

Prevalensi hipertensi pada usia 15 sampai 17 tahun menurut Joint national committee ke tujuh (JNC VII), didapatkan prevalensi nasional sebesar 5,3\% (laki-laki $6,0 \%$ dan perempuan $4,7 \%)$. Prevalensi pada penduduk pedesaan $(5,6 \%)$ lebih tinggi dari perkotaan $(5,1 \%)^{10}$. Profil kesehatan provinsi Aceh ${ }^{11}$, dalam daftar 20 penyakit untuk rawat jalan, hipertensi berada diperingkat kedua dengan jumlah kasus sebanyak 20.467 kasus dan peringkat keempat dengan jumlah kasus sebanyak 1.963 untuk rawat inap di rumah sakit umum provinsi Aceh dengan umur $>18$ tahun. Data dari Dinas Kesehatan Kota Lhokseumawe ${ }^{12}$ didapatkan bahwa hipertensi menempati urutan pertama dari sepuluh penyakit tidak menular terbanyak dengan kelompok usia $>18$ tahun.

Kualitas tidur adalah salah satu faktor yang sangat penting dalam mempertahankan kesehatan selain gaya hidup. Efisiensi tidur yang lelah diketahui dapat berisiko terhadap terjadinya hipertensi dan optimalisasi jam tidur dapat membantu untuk mencegah terjadinya hipertensi. Efek kumulatif kurang tidur yang berkepanjangan atau gangguan tidur juga dikaitkan dengan peningkatan mortalitas dan peningkatan risiko untuk berbagai penyakit kronis termasuk depresi, hipertensi, stroke, diabetes tipe 2, penyakit jantung, dan obesitas ${ }^{13}$. 


\section{METODE PENELITIAN}

Penelitian ini merupakan penelitian observasi analitik dengan pendekatan potong lintang (cross sectional study). Penelitian ini dilakukan di SMA Negeri 2 Kota Lhokseumawe mulai dari bulan Agustus 2015 sampai dengan April 2016. Populasi penelitian ini adalah seluruh siswa SMA Negeri 2 Kota Lhokseumawe pada tahun 2015/2016 yaitu sebanyak 958 siswa. Sampel dalam penelitian ini adalah siswa-siswi SMA Negeri 2 Kota Lhokseumawe yang memenuhi kriteria inklusi dan kriteria eksklusi.Kriteria inklusinya adalah Siswa yang terdata aktif bersekolah pada tahun tersebut, umur 15 sampai 17 tahun, status gizi normal, dan bersedia diwawancarai dan diukur tekanan darahnya. Sementara kriteria eksklusi dalam penelitian ini adalah siswa yang memiliki riwayat penyakit kardiovaskular, riwayat keluarga penderita penyakit kardiovaskular, merokok dan mengkonsumsi alkohol. Sampel diambil dengan menggunakan teknik simple random sampling.Berdasarkan perhitungan besar sampel dengan menggunakan rumus lameshow, maka besar sampel yang dibutuhkan seluruhnya adalah 64 anak dan diambil sebanyak 88 anak. Instrumen yang digunakan dalam penelitian ini terdiri dari, Alat pengukur tekanan darah (sphygmomanometer) merk Riester Nova Presameter ${ }^{\circledR}$ dengan lebar ukuran manset $10 \mathrm{~cm}$ dan panjang $24 \mathrm{~cm}$. Alat auskultasi turbulensi darah yaitu stetoskop merk Littmann® Stethoscopes, kuesioner The Pittsburgh Sleep Quality Index (PSQI) yang mengklasifikasi kualits tidur menjadi dua yaitu kualitas tidur baik dengan skor $\mathbf{5}$ dan kualitas tidur buruk $>5$ melalui pengukuran tujuh komponen seperti respon subjektif kualitas tidur, kemampuan mempertahankan tidur, durasi tidur, kebiasaan tidur, hal-hal yang mengganggu tidur, penggunaan obat tidur, dan tidak bersemangat menjalani aktivitas harian selama satu bulan terakhir. Data primer dalam penelitian ini melalui kuesioner dan pengukuran tekanan darah secara langsung.Peneliti meminta responden mengisi lembar persetujuan, kuesioner kualitas tidur dan lembar data tekanan darah dan menjelaskan isi perpoin di dalam kuesioner satu persatu. Peneliti melakukan pengukuran tekanan darah, tinggi badan dan berat badan setelah responden selesai mengisi kuesioner kualitas tidur. 


\section{HASIL PENELITIAN}

Tabel 1. Karakteristik responden

\begin{tabular}{lcc}
\hline Karakteristik & n & \% \\
\hline Usia & & 35,2 \\
15 Tahun & 31 & 40,9 \\
16 Tahun & 36 & 23,9 \\
17 Tahun & 21 & \\
\hline Jenis Kelamin & & 62,5 \\
\hline Perempuan & 55 & 37,5 \\
Laki-laki & 33 & \\
\hline Tekanan darah & & 83,0 \\
Normal & 73 & 9,1 \\
Pre-hipertensi & 8 & 8,0 \\
Hipertensi stadium 1 & 7 & 59,1 \\
\hline Kualitas tidur & & 40,9 \\
\hline Baik & 52 & \\
Buruk & 36 & \\
\hline
\end{tabular}

Berdasarkan tabel di atas,karakteristik responden berdasarkan jenis kelamin, usia, tekanan darah dan kualitas tidur berjumlah 88 orang. Kelompok usia terbanyak pada usia 16 tahun dan paling sedikit pada kelompok usia 17 tahun. Jenis kelamin terbanyak adalah perempuan.Responden terbanyak memiliki tekanan darah normal dan paling sedikit memiliki hipertensi stadium 1.Responden lebih banyak memiliki kualitas tidur yang baik.

Tabel 2.Karakteristik kualitas tidur berdasarkan kelompok usia responden

\begin{tabular}{|c|c|c|c|c|c|c|}
\hline \multirow{3}{*}{$\begin{array}{c}\text { Usia } \\
\text { (tahun) }\end{array}$} & \multicolumn{4}{|c|}{ Kualitas Tidur } & \multirow{2}{*}{\multicolumn{2}{|c|}{ Total }} \\
\hline & \multicolumn{2}{|c|}{ Baik } & \multicolumn{2}{|c|}{ Buruk } & & \\
\hline & Jumlah & $\%$ & Jumlah & $\%$ & Jumlah & $\%$ \\
\hline 15 & 20 & 64,5 & 11 & 35,5 & 31 & 100,0 \\
\hline 16 & 23 & 63,9 & 13 & 36,1 & 36 & 100,0 \\
\hline 17 & 9 & 42,9 & 12 & 57,1 & 21 & 100,0 \\
\hline
\end{tabular}

Berdasarkan tabel di atas,responden paling banyak dengan kualitas tidur baik berada pada kelompok usia 15 tahun dan kualitas tidur buruk lebih banyak pada kelompok usia 17 tahun 
Tabel 3.Karakteristik kualitas tidur berdasarkan jenis kelamin responden

\begin{tabular}{cccccccc}
\hline \multirow{2}{*}{ Jenis Kelamin } & \multicolumn{4}{c}{ Kualitas tidur } & & \multirow{2}{*}{ Total } \\
\cline { 2 - 6 } & Jumlah & Baik & Buruk & Jumlah & \% & Jumlah & \% \\
\cline { 2 - 7 } & 34 & 61,8 & 21 & 38,2 & 55 & 100,0 \\
Perempuan & 18 & 54,5 & 15 & 45,5 & 33 & 100,0 \\
Laki-laki & 18 &
\end{tabular}

Berdasarkan tabel di atas,menunjukkan responden perempuan paling banyak memiliki kualitas tidur baik dan kualitas tidur buruk lebih banyak didapatkan pada laki-laki.

Tabel 4.Karakteristik tekanan darah

\begin{tabular}{|c|c|c|c|c|c|c|c|c|}
\hline \multirow{3}{*}{$\begin{array}{c}\text { Usia } \\
\text { (tahun) }\end{array}$} & \multicolumn{6}{|c|}{ Tekanan darah } & \multirow{2}{*}{\multicolumn{2}{|c|}{ Total }} \\
\hline & \multicolumn{2}{|c|}{ Normal } & \multicolumn{2}{|c|}{ Pre-hipertensi } & \multicolumn{2}{|c|}{ Hipertensi stadium 1} & & \\
\hline & Jumlah & $\%$ & Jumlah & $\%$ & Jumlah & $\%$ & Jumlah & $\%$ \\
\hline 15 & 26 & 83,9 & 3 & 9,7 & 2 & 6,5 & 31 & 100,0 \\
\hline 16 & 32 & 88,9 & 3 & 8,3 & 1 & 3,8 & 36 & 100,0 \\
\hline 17 & 15 & 71,4 & 2 & 9,5 & 4 & 19,0 & 21 & 100,0 \\
\hline
\end{tabular}

Berdasarkan tabel di atas,persentase responden paling besar dengan tekanan darah normal berada pada kelompok usia 16 tahun. Persentase responden paling besar dengan tekanan darah pre-hipertensi berada pada kelompok usia 15 tahun, dan hipertensi stadium 1 paling banyak pada kelompok usia 17 tahun.

Tabel 5.Karakteristik tekanan darah berdasarkan jenis kelamin responden

\begin{tabular}{|c|c|c|c|c|c|c|c|c|}
\hline \multirow{3}{*}{$\begin{array}{c}\text { Jenis } \\
\text { Kelamin }\end{array}$} & \multicolumn{6}{|c|}{ Tekanan darah } & \multirow{2}{*}{\multicolumn{2}{|c|}{ Total }} \\
\hline & \multicolumn{2}{|c|}{ Normal } & \multicolumn{2}{|c|}{$\begin{array}{c}\text { Pre- } \\
\text { Hipertensi }\end{array}$} & \multicolumn{2}{|c|}{$\begin{array}{l}\text { Hipertensi } \\
\text { stadium } 1\end{array}$} & & \\
\hline & Jumlah & $\%$ & Jumlah & $\%$ & Jumlah & $\%$ & Jumlah & $\%$ \\
\hline Perempuan & 47 & 85,5 & 5 & 9,1 & 3 & 5,5 & 55 & 100,0 \\
\hline Laki-laki & 26 & 78,8 & 3 & 9,1 & 4 & 12,1 & 33 & 100,0 \\
\hline
\end{tabular}

Berdasarkan tabel di atas,responden paling banyak dengan tekanan darah normal adalah perempuan dan hipertensi stadium 1 paling banyak adalah laki-laki. 
Tabel 7.Hubungan kualitas tidur terhadap peningkatan tekanan darah pada remaja

\begin{tabular}{|c|c|c|c|c|c|c|c|c|c|}
\hline \multirow{3}{*}{$\underset{\text { tidur }}{\text { Kualitas }}$} & \multicolumn{6}{|c|}{ Tekanan darah } & \multirow{2}{*}{\multicolumn{2}{|c|}{ Total }} & \multirow{3}{*}{$\underset{\text { value }}{\mathbf{p}}$} \\
\hline & \multicolumn{2}{|c|}{ Normal } & \multicolumn{2}{|c|}{$\begin{array}{c}\text { Pre- } \\
\text { hipertensi }\end{array}$} & \multicolumn{2}{|c|}{$\begin{array}{l}\text { Hipertensi } \\
\text { stadium } 1\end{array}$} & & & \\
\hline & Jumlah & $\%$ & Jumlah & $\%$ & Jumlah & $\%$ & Jumlah & $\%$ & \\
\hline Baik & 45 & 86,5 & 5 & 9,6 & 2 & 3,8 & 52 & 100 & \\
\hline Buruk & 28 & 77,8 & 3 & 8,3 & 5 & 13,9 & 36 & 100 & \\
\hline
\end{tabular}

Berdasarkan tabel di atas,remaja dengan kualitas tidur baik sedikit yang memiliki tekanan darah diatas normal, sedangkan responden yang memiliki kualitas tidur buruk sebanyak 8,3\% memiliki tekanan darah pre-hipertensi dan 13,9\% memiliki tekanan darah hipertensi stadium 1. Hasil uji Chi-Square diperoleh nilai $\mathrm{p}$ value sebesar 0,231 yang berarti Ho diterima atau tidak terdapat hubungan antara kualitas tidur terhadap peningkatan tekanan darah pada remaja di SMA Negeri 2 Lhokseumawe.

\section{PEMBAHASAN}

Penelitian dilakukan di Sekolah Menengah Atas (SMA) Negeri 2 Lhokseumawe didapatkan dari 88 responden didapatkan jenis kualitas tidur terbanyak pada remaja yaitu kualitas tidur baik. Penelitian ini sejalan dengan penelitian Javaheri, pada 238 responden, yang memilikikualitas tidur yang baik sebanyak 177 orang tetapi berbanding terbalik pada penelitian Angkat (2009) ${ }^{14}$ yang didapatkan dari 287 responden, 220 orang memiliki kualitas tidur yang buruk.

Berdasarkan usia, remaja usia 17 tahun terbanyak mengalami kualitas tidur buruk. Prevalensi gangguan tidur setiap tahun cenderung meningkat, hal ini juga sesuai dengan peningkatan usia dan berbagai penyebabnya. Penelitian Doi $\mathrm{dkk}^{15}$, menyatakan bahwa prevalensi gangguan tidur siswa SMP dan SMA bervariasi mulai dari 15,3\% hingga 39,2\%. Penelitian LeBourgeois $\mathrm{dkk}^{16}$ pada remaja di Italia dan Amerika menunjukkan bahwa durasi tidur yang cukup berperan dalam membentuk kualitas tidur yang baik.Penelitian Hansen $\mathrm{dkk}^{17}$ mengatakan bahwa jadwal sekolah menyebabkan remaja kekurangan waktu tidur.Durasi tidur dapat cukup, namun dapat terjadi gangguan dalam kualitas tidur atau perubahan jadwal tidur pada siang hari libur, yaitu tidur lebih larut dan bangun siang dibandingkan hari sekolah.Durasi tidur subjek di hari libur pun 
cenderung memanjang sampai berlebihan.Durasi tidur yang inadekuat sesuai umur merupakan salah satu mekanisme terjadinya gangguan tidur pada anak dan remaja ${ }^{18 .}$

Berdasarkan jenis kelamin, laki-laki lebih banyak mengalami kualitas tidur buruk dibandingkan perempuan. Penelitian ini tidak sejalan dengan penelitian Awwal $\mathrm{dkk}^{19}$, prevalensi gangguan tidur pada remaja usia 12 sampai 15 tahun di SMPN 5 semarang didapatkan jenis kelamin perempuan lebih banyak mengalami kualitas tidur buruk. Salah satu fenomena yang sering terjadi adalah pria memulai tidur lebih lambat dan bangun lebih lambat dibanding wanita.Efek dari keterlambatan memulai tidur berupa kantuk.Menjelang tidur sebaiknya tidak melakukan aktivitas olahraga. Aktivitas olahraga yang terlalu dekat dengan waktu tidur akan menghadirkan pengaruh berupa terganggunya tidur seseorang karena otot tubuh tidak memperoleh kesempatan untuk relaksasi sehingga tidur seseorang tidak sepenuhnya pulas ${ }^{20}$.

Perubahan keadaan bangun dan tidur merupakan suatu proses neuron yang kompleks, banyak faktor internal dan eksternal yang dapat mengganggu. Setiap faktor yang mengganggu ascending reticular activating system (ARAS) dapat meningkatkan keadaan terjaga dan mengurangi kemungkinan untuk tertidur.Berbagai faktor kebiasaan dan perilaku dihubungkan dengan gangguan tidur seperti sering menonton televisi sebelum tidur. Tipe kepribadian yang emosional seperti interaksi anak yang selalu bermasalah dengan orang tua, kurang menghargai pendapat orang tua, berusaha untuk mendapat teman baru, gejala psikiatri seperti depresi, sering sedih, masalah perilaku, stres pasca trauma dan abuse juga dihubungkan dengan masalah tidur yang akan berdampak pada kualitas tidur ${ }^{21}$.

Hasil penelitian terhadap 88 responden berusia 15 sampai 17 tahun yang dilakukan di SMA Negeri 2 Lhokseumawe diperoleh tekanan darah normal sebanyak $83,0 \%$, pre-hipertensi sebanyak 9,1\%, hipertensi stadium 1 sebanyak 8,0\%. Tekanan darah tinggi atau disebut hipertensi pada remaja adalah tekanan darah di atas persentil 95 berdasarkan jenis kelamin dan usia, yaitu hipertensi stadium 1. Menurut Depkes ${ }^{22}$, angka kejadian hipertensi usia 15 sampai 17 tahun di indonesia sebesar 8,4\%. Penelitian Moura tahun 2004 di Maceio, Brazil terhadap 1.253 siswa/siswi yang berusia 7 sampai 17 tahun menemukan 9,4\% anak memiliki tekanan darah tinggi. 
Penelitian prevalensi hipertensi pada remaja sangat bervariasi.Hipertensi primer atau esensial merupakan hipertensi yang tidak dapat dijelaskan penyebabnya. Hal ini dikarenakan banyaknya faktor-faktor yang dapat berperan seperti keturunan, berat badan, respons terhadap stres fisik dan psikologi, abnormalitas transpor kation pada membran sel, hiperaktivitas sistem saraf simpatis, resistensi insulin, serta respon terhadap masukan garam dan kalsium ${ }^{23}$.

Berdasarkan usia, remaja usia 17 tahun terbanyak mengalami tekanan darah tinggi (19,0\%), kemudian diikuti remaja usia 15 tahun(6,5\%), dan 16 tahun $(3,8 \%)$. Penyebab peningkatan tekanan darah pada remaja masih belum diketahui.Banyak faktor yang memungkinkan terjadinya hipertensi esensial pada remaja.Faktor lingkungan juga berperan dalam hipertensi esensial seperti konsumsi garam yang tinggi, stres psikogenik, sosial ekonomi, dan faktor predisposisi lainnya seperti ras dan jenis kelamin ${ }^{24}$.Remaja dengan hipertensi esensial kebanyakan tanpa gejala (asimtomatik) dan sering terdeteksi hanya pada saat pemeriksaan rutin. Remaja yang mengalami hipertensi dan terus berlanjut pada usia dewasa di khawatirkan akan memiliki risiko morbiditas dan mortalitas yang lebih tinggi pada penyakit kardiovaskular ${ }^{25}$.

Berdasarkan jenis kelamin, laki-laki lebih banyak mengalami tekanan darah tinggi $(12,1 \%)$ dibandingkan perempuan $(5,5 \%)$. Penelitian ini sejalan dengan penelitian Sundar JS ${ }^{26}$ di Chennai, Tamilnadu terhadap 400 remaja yang berusia 13 sampai 17 tahun didapatkan jenis kelamin laki-laki lebih banyak mengalami hipertensi dibandingkan perempuan, yaitu 77,9\% laki-laki dan 22,09\% perempuan.Jenis kelamin mempengaruhi tekanan darah pada remaja.Tekanan darah remaja laki-laki cenderung lebih tinggi dibandingkan perempuan ${ }^{9}$.Hormon androgen, seperti testosteron, diduga berperan dalam pengaturan tekanan darah terkait dengan adanya perbedaan pada kedua jenis kelamin tersebut.Hormon ini memungkinkan terjadinya pelepasan renin dengan mengurangi laju filtrtasi glomerulus, meningkatkan reabsorbsi natrium, dan mengurangi penghantaran natrium ke macula densa. Selain itu, peningkatan aktivitas renin dan angiotensin II juga akan terjadi jika hormon androgen menyebabkan peningkatan reninangiotensinogen. Angiotensin II melalui reseptor angiotensin I menyebabkan vasokonstriksi renal dan menstimulasi reabsorbsi natrium pada tubulus proksimal dan 
atau menstimulasi reabsorbsi natrium pada tubulus distal melalui mekanisme hormon aldosteron, hingga akhirnya terjadi peningkatan tekanan darah ${ }^{27}$.

Hasil penelitian, dari 88 responden, didapatkan bahwa kualitas tidur yang baik banyak didapatkan pada tekanan darah yang normal yaitu sebesar $86,5 \%$, pre-hipertensi sebesar 9,6\% dan hipertensi stadium 1 sebesar 3,8\%, sedangkan kualitas tidur yang buruk banyak didapatkan pada tekanan darah yang normal yaitu sebesar 77,8\%, prehipertensi sebesar 8,3\% dan hipertensi stadium 1 sebesar 13,9\%. Penelitian ini didapatkan bahwa tidak ada perbedaan kualitas tidur yang baik maupun buruk $(p>$ 0,10). Penelitian ini bertentangan dengan teori yang menyatakan bahwa gangguan tidur yang terjadi secara terus menerus dapat menyebabkan perubahan fisiologi tubuh yang mengakibatkan ketidakseimbangan antara pengaturan sistem saraf simpatis dan parasimpatis ${ }^{28}$.Selain faktor diatas, faktor-faktor yang yang dapat mempengaruhi terjadinya hipertensi antara lain seperti usia, berat badan, stress dan riwayat keluarga ${ }^{29}$.

Faktor-faktor yang memungkinkan berbedanya dengan hasil penelitian sebelumnya yaitu:

a. Penelitian sebelumnya menggunakan instrumen Wrist Actigraphy yang memiliki ketetapan lebih tinggi dibandingkan menggunakan kuesioner PSQI walaupun kuesioner tersebut sudah baku.

b. Perbedaan aktivitas responden pada penelitian sebelumnya seperti dari segi pola hidup yang memicu gejala insomnia yang lebih sering dialami oleh remaja diluar negeri dari pada penelitian ini.

c. Melakukan pemberitahuan kepada responden 1 bulan atau lebih sebelum penelitian dilakukan agar dicatat jam-jam tidurnya

d. Jenis kelamin pada penelitian sebelumnya hanya dikhususkan pada laki-laki, berbeda dengan penelitian ini yang juga melibatkan jenis kelamin perempuan.

e. Menambahkan kriteria tingkat prestasi yang lebih tinggi karena selain responden dapat menjawab pertanyaan dengan teliti dan sungguh-sungguh, responden yang memiliki tingkat prestasi yang lebih tinggi memiliki aktivitas yang lebih padat dari siswa biasa, sehingga akan sangat mempengaruhi kualitas tidur mereka. 


\section{KESIMPULAN}

Gambaran kualitas tidur buruk terbanyak pada kelompok usia 17 tahun dan kualitas tidur baik terbanyak pada kelompok usia 15 tahun. Gambaran kualitas tidur buruk terbanyak pada laki-laki sedangkan kualitas tidur baik terbanyak pada perempuan sebanyak 61, Gambaran tekanan darah normal terbanyak pada kelompok usia 16 tahun, pre-hipertensi pada kelompok usia 15 tahun dan hipertensi stadium 1 terbanyak pada kelompok usia 17 tahun. Gambaran tekanan darah normal terbanyak pada perempuan dan hipertensi stadium 1 terbanyak pada laki-laki. Kesimpulan dari penelitian ini tidak terdapat hubungan yang signifikan antara kualitas tidur terhadap peningkatan tekanan darah pada remaja. Saran dari penelitian ini adalah bagi peneliti lain yang ingin melanjutkan penelitian mengenai hal yang sama dengan penelitian ini, disarankan untuk melakukan penelitian dengan menggunakan alat ukur kualitas tidur yang lebih akurat, yang memiliki angka reliabilitas yang lebih besar, melakukan pemberitahuan kepada responden 1 bulan atau lebih sebelum penelitian dilakukan agar dicatat jam-jam tidurnya dan menambahkan kriteria tingkat prestasi yang lebih tinggi karena selain responden dapat menjawab pertanyaan dengan teliti dan sungguh-sungguh, responden yang memiliki tingkat prestasi yang lebih tinggi memiliki aktivitas yang lebih padat dari siswa biasa, sehingga akan sangat mempengaruhi kualitas tidur mereka

\section{Ucapan Terima Kasih}

Penulis menyadari jurnal ini dapat terselesaikan dengan baik berkat bantuan dari berbagai pihak, oleh karena itu dengan penuh kesungguhan dan kerendahan hati penulis mengucapkan terima kasih kepadaDr. dr. Rajuddin, Sp.OG, K.FER, dr. Meutia Maulina, M.Si, dr. Cut Sidrah Nadira, M.Sc, dr. Cut Asmaul Husna, M.Si, serta kedua orang tua dan saudara kandung penulis.

\section{DAFTAR PUSTAKA}

1. Dhamayanti M. Seputar kesehatan anak 'Overview adolescent health problems and services', Artikel Ikatan Dokter Anak Indonesia (IDAI).10 September, hlm 1- 
13, dilihat 25 agustus 2015; http://idai.or.id/public-articles/seputar-kesehatananak/over view-adolescent-health-problems-and-services.html.

2. Hassan R, Alatas H. Buku kuliah ilmu kesehatan anak. Balai penerbit Fakultas Kedokteran Universitas Indonesia, Jakarta, 1998.

3. Dalton A. Gangguan tidur. Ilmu kesehatan anak. vol.1, EGC. Jakarta, 2000.

4. Needlman RD. Ilmu Kesehatan Anak Nelson WE. edisi 15, vol. 1. EGC, Jakarta, 2012.

5. Ruffin N. Adolescent Growth and Development, Communications and Marketing College of Agriculture and Life Sciences Virgina Polytechnic Institue and Sate University, accesed 03 October 2015; http://www.nvc.vt. edu/mft/mft2 files/huebner/Adolescent_Growth_and_Development.pdf.

6. Sekartini R, Tanjung MFC. Masalah tidur pada anak. Sari pediatric. Vol.6, Jakarta, 2004.

7. Asmarita I. Hubungan antara kualitas tidur dengan tekanan darah pada pasien hipertensi di rumah sakit umum daerah karanganyar. Naskah publikasi.Universitas Muhammadiyah Surakarta, Surakarta, 2014.

8. Fitriana R, Lipocto NI, Triana V. Faktor risiko kejadian hipertensi pada remaja di wilayah kerja puskesmas rawat inap sidomulyo kota pekanbaru, Jurnal kesehatan masyarakat, FKM Unand, Padang, 2013.

9. Saing JH. Hipertensi pada remaja. Sari pediatric. Vol.6, Medan, 2005.

10. Riset Kesehatan Dasar (RISKESDAS). Penyakit tidak menular 'hipertensi atau tekanan darah tinggi'. Jakarta:Badan penelitian dan pengembangan kesehatan kementrian kesehatan republik indonesia, 2013.

11. Profil kesehatan Provinsi aceh. Daftar 20 penyakit untuk rawat jalan, dilihat juni 2015;

http://www.depkes.go.id/resources/download/profil/PROFIL_KES_PROVINSI _2012/01_Profil_Kes_Prov.Aceh_2012.pdf.

12. Dinas Kesehatan Kota Lhokseumawe. Data kasus dan kematian penyakit tidak menular kota Lhokseumawe, 2015. 
13. Lowry R, Eaton DK, Foti K, Eily LM, Perry G, Galuska DA. Association of sleep duration with obesity among US high school students, Journal of obesity, accesed 08 November 2015; http://www.hindawi.com/ journals/jobe/2012/476914.

14. Angkat DN.Hubungan antara kualitas tidur dengan tekanan darah pada remaja usia 15-17 tahun di sma negeri 1 tanjung morawa. Karya tulis ilmiah, Universitas Sumatera Utara, Medan, 2009.

15. Doi Y, Minowa M, Ochida T, Osaki Y, Suzuki KD. An epidemiologic study of self-reported sleep problems among japanes adolescents. hlm 85-978, 2004.

16. LeBourgeois MK, Giannoti F, Cortesi F, Wolfson AR, Harsh J. The relationship between reported sleep quality and sleep hygiene in Italia and America $\begin{array}{llll}\text { adolescent. } & \text { Pediatric, } & \text { Accesed } & \text { Mei }\end{array}$ http://pediatrics.aappublications.org/cgi/ content/full/115/1/S1/257.

17. Hansen M, Janssen I, Schiff A, Zee CP, Dubocovich ML. The impact of school daily schedul on adolescent sleep. Pediatrics. Accesed 11 Mei 2016; http://pediatric s.aappublications.org/content/115/6/1555.full.

18. Mindel JA, Owens JA. A sleep in the pediatric practice in Diagnostic and managment of sleep problems. Lippincott; Williams \& Wilkins, 2003.

19. Awwal H, Hartanto F, Hendrianingtas M. Prevalensi gangguan tidur pada remaja usia 12 sampai 15 tahun: studi pada siswa SMPN 5 Semarang, Media medika muda, Vol. 4, Tembalang-semarang,2015.

20. Maas JB. Power sleep. Bandung; Penerbit kaifa,2002.

21. Batubara JRL. Adolescent development (perkembangan remaja). Sari pediatric. Vol. 12, Jakarta,2010.

22. Depkes RI. Laporan Hasil Riset Kesehatan Dasar Tahun 2007. Jakarta,2008.

23. UKK IDAI. Konsensus Tatalaksana Hipertensi Pada Anak. Jakarta,2011.

24. Gauthier B, Edelmann CMJ, Barnet HL. Hipertension. Nephrologi and Urology for the pediatrician. Boston; Little Brown and Company, 1982.

25. Supartha M, Suarta IK, Winaya IBA. Hipertensi pada anak. Majalah Kedokteran Indonesia, Vol. 59, No. 5. 2009. 
26. Sundar JS. Prevalence and determinants of hypertension among urban school children in the age group of 13-17 years in, Chennai, Tamilnadu. IOS Journal of Dental and Medical Sciences. Vol. 8, No. 3. 2013.

27. Reckelhoff $\mathbf{J}$ 2001. Gender differences in the regulation of blood pressure. Journal of the American Heart Association. Vol. 37,2001.

28. Wendy. Marital quality and marital bed: examining the covariation between relationship quality and sleep. Accesed: 27 April 2016: http://www .ncbi. nlm.nih.gov/pubmed/17854738.2007.

29. Hartono B. Hipertensi the silent killer, Accesed 11 Mei 2016; http://www.in ash.or.id. 